\title{
Sintesis Aluminium Matrix Composites (AMC) Berpenguat Sinter Silika dengan Metode Powder Metallurgy
}

\author{
Zeflianto Rhomar ${ }^{*}$, Ardian Putra, Astuti \\ Laboratorium Fisika Bumi, Jurusan Fisika, FMIPA, Universitas Andalas \\ Kampus Unand, Limau Manis, Padang, 25163 \\ "Ijef19@gmail.com
}

\begin{abstract}
ABSTRAK
Aluminium Matrix Composites (AMC) telah disintesis dari aluminium serbuk sebagai matriks dan sinter silika (berbentuk serbuk) sebagai pengisi yang berasal dari mata air panas Sentral, Solok Selatan, Sumatera Barat dengan menggunakan metode powder metallurgy. Sintesis dilakukan dengan cara mencampur aluminium dengan sinter silika, dilakukan 4 variasi massa, yaitu $80 \mathrm{~g}: 5 \mathrm{~g} ; 80 \mathrm{~g} 10 \mathrm{~g} ; 80 \mathrm{~g}$ : $15 \mathrm{~g}$ dan $80 \mathrm{~g}$ : $20 \mathrm{~g}$ dengan menggunakan media pelarut, yaitu metil alkohol. Campuran diaduk selama 210 menit dengan menggunakan hot plate magnetic stirrer, kemudian endapan yang tersisa dikeringkan dengan oven selama 60 menit dengan temperatur $100^{\circ} \mathrm{C}$. Endapan yang telah dikeringkan kemudian digerus sebanyak 0,5 g untuk masing-masing sampel dikompaksi sehingga berbentuk pelet. Pelet disintering dengan furnace selama 180 menit dengan temperatur $600^{\circ} \mathrm{C}$. Pelet yang telah disintering diukur massa kering, diameter, tinggi dan massa basahnya setelah dicelupkan ke dalam air selama 12 menit kemudian dapat dihitung nilai densitas dan porositas setelah sintering dan porositasnya. Dari hasil perhitungan, densitas komposit setelah sintering cenderung memiliki nilai yang lebih kecil dibandingkan densitas komposit sebelum sintering. Berdasarkan perhitungan dan pengujian didapatkan persentase porositas dan kuat tekan, yaitu 40,72\% dan 0,078 MPa untuk sampel 1, 39,12\% dan 0,098 MPa untuk sampel 2, 39,51\% dan 0,088 MPa untuk sampel 3 dan 44,45\% dan 0,069 MPa untuk sampel 4. Berdasarkan hubungan kuat tekan dan porositas didapatkan hubungan $\sigma=0,8721 \mathrm{e}^{-5,757 \mathrm{P}}$ dimana 0,8721 MPa menyatakan kuat tekan komposit tanpa pori.

Kata kunci: AMC, densitas, pelet, porositas, powder metallurgy, sintering
\end{abstract}

\section{ABSTRACT}

Aluminum Matrix Composites (AMC) have been synthesized from aluminum powder as matrix and silica sinter (in powder form) as a filler derived from the hot springs of the Central, South Solok, West Sumatra using powder metallurgy method. Synthesis is done by mixing aluminum with silica sinter, made four variations of the mass of $80 \mathrm{~g}: 5 \mathrm{~g} ; 80 \mathrm{~g} 10 \mathrm{~g} ; 80 \mathrm{~g}: 15 \mathrm{~g}$ and $80 \mathrm{~g}: 20 \mathrm{~g}$ using a solvent media, namely methyl alcohol. The mixture was stirred for 210 minutes using a magnetic stirrer, and then the remaining sludge was dried in an oven for 60 minutes at $100^{\circ} \mathrm{C}$. The precipitate was dried then crushed as much as $0.5 \mathrm{~g}$ for each sample compacted to form pellets. Sintering furnace pellets with over 180 minutes at a temperature of $600^{\circ} \mathrm{C}$. Sintering pellets that have been measured dry mass, diameter, height and mass of wet after immersion in water for 12 minutes and then calculated the density and porosity after sintering and porosity. From the calculation, the density of the composite after sintering tend to have a smaller value than the density of the composite prior to sintering. Based on the calculations and testing obtained the percentage of porosity and compressive strength, which is $40.72 \%$ and $0.078 \mathrm{MPa}$ for samples 1 , $39.12 \%$ and $0.098 \mathrm{MPa}$ for sample 2, 39.51\% and $0.088 \mathrm{MPa}$ for samples 3 and $44.45 \%$ and $0.069 \mathrm{MPa}$ to sample 4. Based on the relationship between compressive strength and porosity, the equation $\sigma=$ $0,8721 e^{-5,757 P}$ shows that AMC composites has 0,8721 MPa compressive strength without pore.

Keywords: AMC, density, pellets, porosity, powder metallurgy, sintering

\section{PENDAHULUAN}

Komposit adalah material hasil kombinasi makroskopik dari dua atau lebih komponen yang berbeda, memiliki interface diantaranya dengan tujuan mendapatkan sifat-sifat fisik dan mekanis tertentu yang lebih baik dibandingkan dengan sifat masing-masing komponen penyusunnya (Sahari, dkk., 2009). Berdasarkan bahan matriksnya, komposit dapat diklasifikasikan menjadi empat, yaitu Polymer Matrix Composites (PMC), Metal Matrix Composites (MMC), Carbon-Carbon Composites (CCC) dan Ceramic Matrix Composites (CMC). MMC memiliki beberapa kelebihan, yaitu suhu operasi yang tinggi, memiliki kekuatan yang tinggi dan konduktivitas termal yang baik. Bahan matriks yang biasa digunakan adalah paduan aluminium, magnesium, titanium, tembaga dan untuk bahan yang berserat biasanya digunakan karbon dan alumina. Ada beberapa aplikasi dari MMC contohnya AMC, yaitu pada 
komponen mobil, struktur aerospace, pesawat ulang-alik, struktur kapal laut dan lain-lain (Vijaya dan Rangarajan, 2003).

Aluminium (Al) memiliki beberapa kelebihan lainnya, yaitu ringan dan mudah dibentuk (casting). Logam Al sebagai unsur, bila ditinjau dari sifat mekanik, seperti nilai kekerasan (hardness) sangat rendah, oleh karena itu logam Al sebagai material memiliki banyak kelemahan terutama kekuatan mekanik, kekakuan, dan koefisien muainya (Shi, 2001). Kelemahan logam Al disiasati dengan cara memadukannya dengan senyawa lain, agar didapatkan material baru yang memiliki karakteristik lebih baik. Salah satu cara untuk meningkatkan nilai kekerasan logam, maka perlu dilakukan penguatan pada logam tersebut, yaitu dengan cara ditambahkan dengan material yang keras seperti $\mathrm{SiO}_{2}$ (silikon dioksida), $\mathrm{SiC}$ (silikon karbida), $\mathrm{TiC}$ (titanium karbida) dan $\mathrm{ZrO}_{2}$ (zirkonium dioksida) (Idris, dkk., 2003).

Silika $\left(\mathrm{SiO}_{2}\right)$ tersusun atas atom silikon dan oksigen yang berasal dari fluida hidrotermal yang diendapkan ketika fluida mencapai titik jenuh. $\mathrm{SiO}_{2}$ merupakan material yang menarik dan memiliki kekuatan mekanik dan stabilitas termal yang tinggi, akan tetapi tidak dapat diaplikasikan langsung karena $\mathrm{SiO}_{2}$ mengandung silanol ( $\left.\mathrm{Si}-\mathrm{OH}\right)$ dan siloksan ( $\mathrm{Si}-\mathrm{O}-\mathrm{Si}$ ) yang sangat responsif terhadap proses adsorpsi (Ngatijo, 2013). Schumacher (1991) dalam Apriyanto dkk (2008) menyatakan bahwa $\mathrm{SiO}_{2}$ memiliki kelebihan, yaitu ketahanan termal dan kekakuan yang tinggi. Apabila material ini digunakan sebagai penguat dan dipadukan dengan aluminium sebagai matriks maka akan dapat dihasilkan komposit yang memiliki densitas yang lebih besar dan ketahanan korosi yang tinggi, ringan serta kemampuan bahan untuk dibentuk yang baik. Densitas komposit dapat dihitung dengan Persamaan 1.

$$
\rho=\frac{m}{V}
$$

dengan $\rho$ merupakan densitas bahan $\left(\mathrm{g} / \mathrm{cm}^{3}\right), m$ merupakan massa bahan $(\mathrm{g})$ dan $V$ merupakan volume bahan $\left(\mathrm{cm}^{3}\right)$. Aluminium Matrix Composites (AMC) adalah jenis material komposit logam dengan aluminium sebagai matrik dan dalam penelitian ini digunakan $\mathrm{SiO}_{2}$ sebagai penguatnya. AMC mempunyai prospek pengembangan yang bagus, didasari oleh sifat-sifatnya seperti persentase porositas yang rendah, kekerasan yang tinggi, bahan dasar yang mudah didapatkan, dengan harga yang ekonomis (Suyanto, 2015). Persentase porositas dapat dihitung dengan Persamaan 2.

$$
P=\left(\frac{m_{b}-m_{s}}{V_{s}}\right) \times\left(\frac{1}{\rho_{\text {air }}}\right) \times 100 \%
$$

dengan $P(\%)$ merupakan porositas bahan, $m_{b}$ merupakan massa basah bahan setelah sintering $(\mathrm{g}), m_{s}$ merupakan massa kering bahan setelah sintering $(\mathrm{g}), V_{s}$ merupakan volume bahan setelah sintering $\left(\mathrm{g} / \mathrm{cm}^{3}\right)$ dan $\rho_{\text {air }}$ merupakan densitas air $\left(\mathrm{g} / \mathrm{cm}^{3}\right)$. Kuat tekan suatu material didefinisikan sebagai kemampuan material dalam menahan beban atau gaya mekanik sampai terjadinya kegagalan (failure). Pengujian kekuatan tekan dilakukan dengan menggunakan mesin tekan dan hasil massa beban maksimum akan terbaca dalam satuan ton. Benda uji diletakkan pada bidang tekan mesin kemudian pembebanan dilakukan secara perlahan sampai benda uji mengalami fraktur (keretakan) (Dawling, 1999). Kuat tekan dapat dihitung dengan Persamaan 3.

$$
\sigma=\frac{F}{A}
$$

dengan $\sigma$ merupakan kuat tekan bahan $\left(\mathrm{N} / \mathrm{m}^{2}\right), F$ merupakan beban maksimum yang diberikan (N) dan $A$ merupakan luas bidang permukaan $\left(\mathrm{m}^{2}\right)$ Pada penelitian ini akan dilakukan pembuatan AMC dengan aluminium sebagai matriks dan sinter silika sebagai penguatnya dengan menggunakan metode powder metallurgy.

\section{METODE}

Peralatan yang digunakan dalam penelitian ini adalah beaker glass, pipet spatula logam, cawan keramik, lumpang, timbangan digital, moisture balance, furnace, hot plate magnetic 102 
stirrer, oven, ayakan 200 mesh, jangka sorong, alat kompaksi dan alat uji kuat tekan. Bahan yang digunakan adalah aluminium, sinter silika, etilen glikol, metil alkohol dan aquades. Sampel sinter silika diambil dari sumber mata air panas Sentral, Sapan Maluluang, Solok Selatan, Sumatera Barat.

Sinter silika digerus dan diayak menggunakan ayakan 200 mesh, kemudian sinter silika ditimbang dengan empat variasi yaitu $5 \mathrm{~g}, 10 \mathrm{~g}, 15 \mathrm{~g}, 20 \mathrm{~g}$ dan untuk aluminium ditimbang sebanyak empat kali dengan massa tetap yaitu $80 \mathrm{~g}$. Aluminium dan sinter silika yang telah di timbang disintesis menggunakan metode powder metallurgy dengan langkah-langkah sebagai berikut:

1. Aluminium serbuk sebanyak $80 \mathrm{~g}$ dan sinter silika sebanyak $5 \mathrm{~g}$ dicampur dan dimasukkan ke dalam beaker glass.

2. Metanol ditambahkan ke dalam campuran yang sudah di dalam beaker glass sebanyak 300 $\mathrm{ml}$.

3. Beaker glass yang berisi campuran aluminium dengan silika diletakkan di atas hot plate magnetic stirrer, setelah itu diatur temperatur pengadukkan $80{ }^{\circ} \mathrm{C}$ dan kecepatan pengadukkan $3 \mathrm{rpm}$ kemudian magnetic bar dimasukkan ke dalam larutan yang berfungsi sebagai pengaduknya dan waktu pengadukkan diatur selama 210 menit.

4. Setelah proses pengadukkan selesai selanjutnya endapan campuran aluminium dan sinter silika dikeringkan menggunakan oven selama 60 menit dengan temperatur $100{ }^{\circ} \mathrm{C}$.

5. Endapan yang telah kering dihaluskan dengan menggunakan alu dan lumpang kemudian campuran ditimbang sebanyak $0,5 \mathrm{~g}$ untuk dicetak menjadi pelet.

6. Campuran yang telah berbentuk pelet (AMC) ditimbang massanya kemudian diukur diameter dan tebalnya.

7. AMC disintering menggunakan furnace dengan waktu tahan selama 3 jam dan temperatur $600{ }^{\circ} \mathrm{C}$.

8. AMC yang telah disintering kemudian ditimbang kembali massanya (massa kering AMC) dan diukur diameter dan tebalnya.

9. AMC dicelupkan ke dalam air sebanyak $50 \mathrm{ml}$ selama 2 menit lalu ditimbang kembali massanya (massa basah AMC) kemudian AMC dikeringkan.

10. Persentase porositas, densitas AMC sebelum dan setelah sintering dihitung.

11. Dilakukan uji kuat tekan.

12. Langkah 1 sampai 12 diulang untuk perbandingan massa aluminium dan sinter silika $80 \mathrm{~g}$ : $10 \mathrm{~g}, 80 \mathrm{~g}: 15 \mathrm{~g}$ dan $80 \mathrm{~g}: 20 \mathrm{~g}$.

\section{HASIL DAN DISKUSI}

\subsection{Densitas AMC sebelum dan setelah sintering}

Densitas AMC sebelum sintering berkisar dari $1,136 \mathrm{~g} / \mathrm{cm}^{3}-1,258 \mathrm{~g} / \mathrm{cm}^{3}$ dan densitas AMC setelah sintering berkisar dari $1,075 \mathrm{~g} / \mathrm{cm}^{3}-1,289 \mathrm{~g} / \mathrm{cm}^{3}$ (Tabel 1). Densitas AMC sebelum sintering mengalami penurunan seiring penambahan massa sinter silika. Hal ini terjadi karena faktor tekanan yang diberikan pada setiap sampel sama yang mengakibatkan tebal pelet yang terbentuk cenderung bertambah besar seiring bertambahnya massa sinter silika yang digunakan. Hal ini sesuai (Apriyanto, dkk., 2008) yang menyatakan bahwa semakin bertambah massa silika yang digunakan maka densitas AMC sebelum sintering akan semakin mengecil.

Berdasarkan Tabel 1 dapat dilihat bahwa densitas AMC setelah sintering cenderung lebih kecil dibandingkan dengan densitas AMC sebelum sintering. Hal ini terjadi karena proses sintering yang dilakukan mengakibatkan diameter dan tebal AMC yang dihasilkan menjadi lebih besar yang menyebabkan volume menjadi lebih besar sehingga densitas setelah sintering yang dihasilkan lebih kecil. 
Tabel 1 Hasil densitas AMC sebelum dan sesudah sintering

\begin{tabular}{ccc}
\hline \multirow{2}{*}{$\mathbf{~ A l ~ : ~} \mathbf{~ S ~ S i O}_{2}$} & \multicolumn{2}{c}{ Densitas AMC } \\
\cline { 2 - 3 }$(\mathbf{g}: \mathbf{g})$ & sebelum sintering $\left(\mathbf{g} / \mathbf{c m}^{\mathbf{3}}\right)$ & setelah sintering $\left(\mathbf{g} / \mathbf{c m}^{\mathbf{3}}\right)$ \\
\hline $80: 5$ & 1,258 & 1,093 \\
$80: 10$ & 1,196 & 1,075 \\
$80: 15$ & 1,166 & 1,133 \\
$80: 20$ & 1,136 & 1,289 \\
\hline
\end{tabular}

\subsection{Porositas AMC}

Porositas dihitung menggunakan Persamaan 2. Porositas AMC setelah sintering berkisar dari 39,12\%-44,75\%. Dari Tabel 2 terlihat bahwa sampel 2 memiliki porositas yang paling kecil dibandingkan sampel yang lain, yaitu sebesar 39,12\% dengan komposisi massa silika yang digunakan $10 \mathrm{~g}$. Sampel 4 yang memiliki porositas tertinggi dibandingkan sampel yang lain, yaitu sebesar 44,45\% dengan komposisi massa silika yang digunakan $20 \mathrm{~g}$.

Tabel 2 Porositas AMC

\begin{tabular}{ccc}
\hline \multirow{2}{*}{ Sampel } & $\begin{array}{c}\text { m Al : } \mathbf{~ m ~ S i O} \\
(\mathbf{g}: \mathbf{g})\end{array}$ & $\begin{array}{c}\text { Porositas AMC } \\
(\boldsymbol{\%})\end{array}$ \\
\hline 1 & $80: 5$ & 40,72 \\
2 & $80: 10$ & 39,12 \\
3 & $80: 15$ & 39,51 \\
4 & $80: 20$ & 44,45 \\
\hline
\end{tabular}

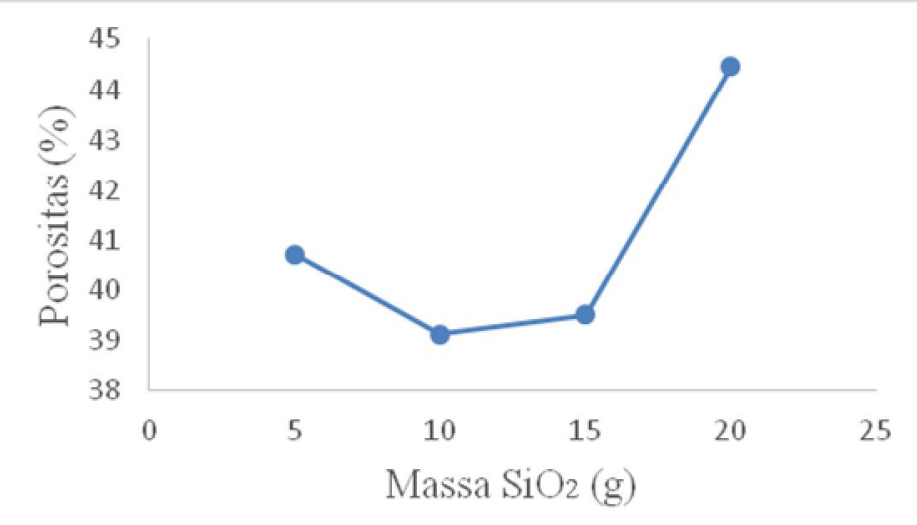

Gambar 1 Hubungan massa silika terhadap porositas AMC setelah sintering

Hubungan massa silika terhadap porositas AMC setelah sintering dapat terlihat pada Gambar 1. Pada Gambar 1 terlihat bahwa tren persentase porositas cenderung naik seiring dengan bertambahnya massa silika yang digunakan. Hal ini terjadi karena perbandingan antara tinggi $(t)$ dengan diameter $(D)$ yang semakin berkurang sehingga persentase porositas meningkat. Hal ini sesuai dengan (Karima, dkk., 2014) yang menyatakan perbandingan $t / D$ berbanding terbalik dengan porositas yang dihasilkan yaitu seiring dengan bertambahnya rasio $\mathrm{t} / \mathrm{D}$, nilai persentase porositas cenderung mengalami penurunan.

\subsection{Kuat tekan AMC}

Kuat tekan diukur dengan alat hydraulic okada. Kuat tekan AMC yang paling rendah sebesar 0,069 MPa yaitu pada sampel dengan penambahan sinter silika sebanyak 20 g. Kuat tekan AMC yang paling tinggi sebesar 0,098 MPa yaitu pada sampel dengan penambahan sinter silika sebanyak $10 \mathrm{~g}$. Kuat tekan dari AMC dapat dilihat pada Tabel 3. Pada Tabel 3 terlihat bahwa kuat tekan AMC yang didapatkan cenderung menurun seiring dengan penambahan massa sinter silika yang digunakan. Hal ini terjadi karena persentase porositas yang didapatkan semakin besar sehingga daerah pori yang menjadi konsentrasi tekanan semakin banyak ketika 
pelet dikenakan beban mekanik yang mengakibatkan kuat tekan yang didapatkan semakin rendah.

Tabel 3 Kuat tekan AMC

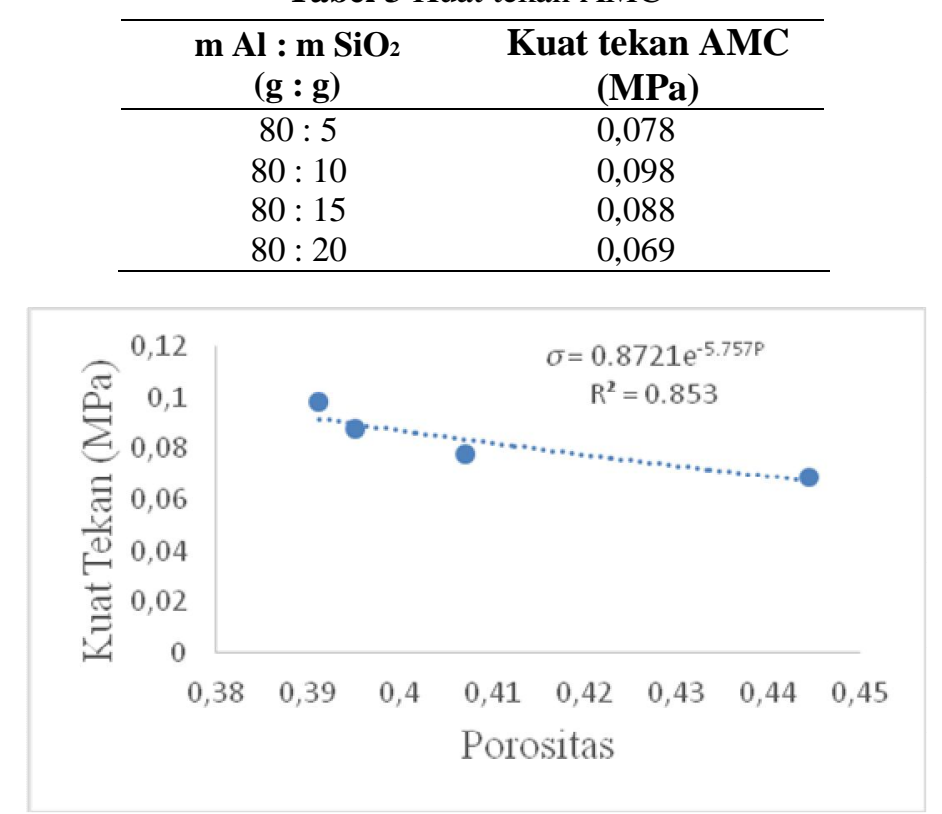

Gambar 2 Hubungan porositas terhadap kuat tekan AMC

Hubungan porositas terhadap kuat tekan AMC dapat terlihat pada Gambar 2. Dari Gambar 2 terlihat bahwa nilai kuat tekan cenderung menurun dengan kenaikan porositas. Pola yang dihasilkan berupa persamaan eksponensial dengan persamaan $\sigma=0,8721 \mathrm{e}^{-5,757 \mathrm{P}}$, dengan $\sigma$ adalah kuat tekan (MPa) dan $P$ adalah porositas $(\%), \sigma_{0}=0,8721, b_{1}=5,757$, dengan koefisien korelasi 0,853. Konstanta 0,8721 menunjukan nilai kuat tekan AMC tanpa pori, sedangkan 5,757 menunjukan karakteristik eksponensial yang tergantung dari bagaimana tumpukan material di dalamnya. Magdeski (2010) mendapatkan konstanta $b_{1}=4,46$ pada sinter alumina, menunjukan AMC pada penelitian ini memiliki konstanta $b_{1}$ yang lebih tinggi.

Van Vlack (1994) yang menyatakan semakin besar porositas yang terukur maka semakin rendah kekuatan suatu bahan. Persentase porositas tertinggi (memiliki pori yang lebih banyak) pada sampel 4 sebesar 44,75\% menghasilkan kuat tekan paling kecil yaitu 0,069 MPa dan persentase porositas terendah (memiliki pori yang lebih sedikit) pada sampel 2 sebesar 39,12\% menghasilkan kuat tekan yang paling besar yaitu 0,098 MPa.

\section{KESIMPULAN}

Berdasarkan hasil penelitian ini dapat diketahui bahwa penambahan sinter silika menghasilkan densitas setelah sintering berkisar dari $1,093 \mathrm{~g} / \mathrm{cm}^{3}$ sampai $1,289 \mathrm{~g} / \mathrm{cm}^{3}$ dan porositas berkisar $39,12 \%$ sampai $44,45 \%$. Kuat tekan yang dihasilkan antara 0,069 MPa sampai 0,098 MPa. Berdasarkan hubungan antara kuat tekan dan porositas $\sigma=0,8721 \mathrm{e}^{-5,757 \mathrm{P}}$ diketahui bahwa kuat tekan AMC tanpa pori didapatkan sebesar 0,8721 MPa.

\section{DAFTAR PUSTAKA}

Apriyanto, A.K., Arifin, M.Z., Lubis, H.I., Isra, R., 2008, Pemanfaatan Abu Sekam Padi sebagai Bahan Baku Penguat Komposit Bermatriks Aluminium (AMCs) untuk Aplikasi Bahan Komponen Otomotif, Laporan PKM-Penelitian, PKM-Penelitian, Institut Teknologi Sepuluh November, Surabaya.

Dawling, E.N, 1999, Mechanical Behavior of Material, Second Edition, Prentice Hall International INC, New Jersey.

Idris, J., Salim, F., Suliman, Z., Osman, E., 2003, Kajian Sifat Keausan dan Kekerasan Komposit Matriks Aluminium, Jurnal Teknologi (JT), 38 (A), hal 11-24. 
Karima, H., Suprapto, W., Sonief, A.A., 2014, Pengaruh Besar Tekanan Compacting pada Silinder Serbuk Duralumin Powder Metallurgy terhadap Kekerasan dan Porositas, Jurnal Mahasiswa Mesin (JMM), Vol.5, No.16.

Magdeski, J. S., 2010, The Porosity Dependence of Mechanical Properties of Sintered Alumina, Journal of the university of chemical technology and metallurgy, Vol.45, No.2, hal 143148

Ngatijo, 2013, Sintesis Silika Termodifikasi Amin dan Aplikasinya sebagai Adsorben Ion Tembaga (II), Prosiding Semirata, Lampung.

Sahari, G.N.A., Zulfia, A., Siradj, E.S., 2009, Pengaruh Mg terhadap Kekerasan Komposit Matriks Leramik $\mathrm{Al}_{2} \mathrm{O}_{3} / \mathrm{Al}$, MAKARA Vol. 13, No.1, hal 39-44.

Shi, Z., 2001, The Oxidation of Particle and Its Interfacial Characteristics in Al-Matrix Composites, Journal of Material Science 36, pp 2441-2449, Kluwer Academic Publisher.

Suyanto, 2015, Analisa Ketangguhan Komposit Aluminium Berpenguat Serbuk SiC, Jurnal SIMETRIS, Vol.6, No.1, Program Studi Teknik Bangunan Kapal Akademi Teknik Perkapalan (ATP) Veteran.

Van Vlack, L.H, 1994, Ilmu dan Teknologi Bahan, Edisi Kelima, (ditermahkan oleh : Sriati Djaprie), Erlangga, Jakarta

Vijaya, S. dan Rangarajan, G., 2003, Materials Science, Tata McGraw-Hill, New Delhi. 